\title{
Enabling kinetically fast activation of carbon nanotube@nickel selenide through pore-phase dual regulation in aqueous zinc battery
}

\author{
Hao Mei ${ }^{1}$, Haobing Zhang ${ }^{1}$, Ziyi $\mathrm{Li}^{1}$, Ling Zhang ${ }^{1}$, Xiaoqing $\mathrm{Lu}^{1}$, Ben $\mathrm{Xu}^{1,2^{*}}$ and Daofeng Sun ${ }^{{ }^{*}}$
}

\begin{abstract}
Metal chalcogenide compounds can be used as high-performance cathodes for aqueous $\mathrm{Zn}$ batteries. However, the low accessible surfaces and violent volumetric expansion limit their properties and applications. To address these, phase-engineering strategies coupled with a hollow structure were applied to regulate the adsorption/desorption of $\mathrm{OH}^{-}$on the electrode surface and enhance the electrochemical performance. In this study, using a Se@C nanorod template, a series of carbon nanotube (CNT)-supported nickel selenides, including cubic $\mathrm{NiSe}_{2}, \mathrm{NiSe}_{2} / \mathrm{Ni}_{0.85} \mathrm{Se}$ composites, and hexagonal $\mathrm{Ni}_{0.85} \mathrm{Se}$, were synthesized through an in situ selenylation process for the first time. Due to the large specific surface, high porosity, and hollow carbon skeleton, the optimized $\mathrm{NiSe}_{2} / \mathrm{Ni}_{0.85} \mathrm{Se} / \mathrm{CNT}$ has a high specific capacity of $616 \mathrm{Cg}^{-1}$, excellent rate capability, and stable cycling performance. In addition, its inside Faradic mechanism was investigated using a series of ex situ characterizations and density functional theory calculations. Thus, the fabricated $\mathrm{Ni} / / \mathrm{Zn}$ battery presents a high energy density of $311.4 \mathrm{~W} \mathrm{~h} \mathrm{~kg}$ at $3485 \mathrm{~W} \mathrm{~kg}^{-1}$ and long cycling life. This study offers an ingenious strategy for designing nickel selenide electrodes and deeper perception for its Faradic mechanism in alkaline $\mathrm{Zn}$ battery.
\end{abstract}

Keywords: aqueous zinc battery, nickel selenide, hollow structure, in situ selenylation

\section{INTRODUCTION}

For the past decades, the explosion and spontaneous combustion of portable electronic devices boosted the development of electrochemical storage devices, most especially lithium-ion (Liion) batteries [1]. However, the present commercial Li-ion batteries require flammable organic electrolytes; thus, their safety issues are attracting attention [2-4]. Aqueous energy storage equipment (AESE) is capable of tackling the problem at the source [5]. Presently, diverse new-type AESEs, such as aqueous lithium-/sodium-/potassium-/magnesium-/zinc-ion batteries, are emerging and have been studied [6-8]. Among them, aqueous $\mathrm{Zn}$-ion batteries, because of their unique superiority, including abundance, low cost, and relatively low redox potential $(-1.38 \mathrm{~V} v s . \mathrm{Hg} / \mathrm{HgO})$, are promising for practical applications [9-11]. Moreover, metallic $\mathrm{Zn}$ can be used as an anode for an aqueous $\mathrm{Zn}$ battery, undergoing reversible $\mathrm{Zn}(\mathrm{OH})_{4}{ }^{2-} / \mathrm{Zn}^{0}$ redox kinetics and exhibiting an ultrahigh the- oretical capacity in an alkaline electrolyte $\left(824 \mathrm{mAhg}^{-1}\right.$ or $5855 \mathrm{~mA} \mathrm{~h} \mathrm{~cm}^{-3}$ ) [12-16]. However, there are plenty of optional materials for the cathodes of aqueous $\mathrm{Zn}$ batteries, and they determine the performances of the devices [7,17-19]. Therefore, the rational structure design and optimization of cathode materials are important for improving the performance of $\mathrm{Zn}$ batteries [20-22].

As a class of typical metal chalcogenides, nickel-based selenides, due to their tunable electronic configuration, multiple oxidation states, and rich reserves, are being investigated in energy storage and conversion fields, such as batteries and electrocatalysts [23-26]. Attributed to their intrinsic high electrical conductivity and excellent redox activity, nickel-based selenides are potential high-performance electrode materials in alkaline $\mathrm{Zn}$ batteries [27]. However, it is challenging that nickel selenides suffer from their low surface area and violent volumetric expansion effect during charging, leading to unsatisfactory capacity and cycle performance [28-30]. In principle, the energy storage of nickel selenides is dominated by the hydroxylike structure formed during electrochemically induced reconstruction at the electrode/electrolyte interfaces [31]. Therefore, regulating the adsorption/desorption of $\mathrm{OH}^{-}$on the electrode surface could enhance the overall electrochemical performance [32]. To achieve this, it has been demonstrated that phase engineering, such as heterogeneous structure, can accelerate charge transfer and reinforce the interfacial redox activity during charging/discharging [33]. As for nickel selenides possessing multiple phases, including cubic $\mathrm{NiSe}_{2}$ and hexagonal $\mathrm{Ni}_{0.85} \mathrm{Se}$, using a phase-engineering strategy to optimize the formation of a hydroxy-like structure at the nickel selenides/alkaline electrolyte interface is important.

Designing hollow nanostructures is an effective strategy to create more active sites, improve inherent electrochemical reactivity, and enhance the overall properties of electrode materials. In this study, using a Se@C nanorod template, a series of carbon nanotube (CNT)-supported nickel selenides, including cubic $\mathrm{NiSe}_{2}$, cubic $\mathrm{NiSe}_{2} /$ hexagonal $\mathrm{Ni}_{0.85} \mathrm{Se}$ composites, and hexagonal $\mathrm{Ni}_{0.85} \mathrm{Se}$ (referred to as CNT@CNS, CNT@CHNS, CNT@HNS), were synthesized through an in situ selenylation process for the first time. The whole process involves the coating of $\mathrm{Ni}(\mathrm{OH})_{2}$ nanoflakes on Se@C nanorods coupled with in situ selenization of Se@C-Ni(OH)$)_{2}$. As a cathode electrode for the aqueous Zn battery, the optimized CNT@CHNS electrode performs the following superiorities: (1) increasing the specific area, porosity, and tubular structure, guaranteeing the rapid diffusion

\footnotetext{
${ }^{1}$ College of Science, School of Materials Science and Engineering, China University of Petroleum (East China), Qingdao 266580, China

${ }^{2}$ Key Laboratory of Structural Chemistry, Fujian Institute of Research on the Structure of Matter, Chinese Academy of Sciences, Fuzhou 350002, China

* Corresponding authors: (emails: dfsun@upc.edu.cn (Sun D); benxu@upc.edu.cn (Xu B))
} 
of electrolyte, and enhancing the ion conductivities; (2) the carbon skeleton and the $\mathrm{NiSe}_{2} / \mathrm{Ni}_{0.85}$ Se heterostructure promote the charge transfer; (3) the kinetically fast formation of a hydroxy-like structure at the interfaces. Therefore, it presents a high specific capacity $\left(616 \mathrm{Cg}^{-1}\right.$ at $\left.2 \mathrm{Ag}^{-1}\right)$, excellent rate capability, and stable cycling performance (3000 cycles, $80 \%$ capacity retention). In addition, the as-fabricated $\mathrm{Ni} / / \mathrm{Zn}$ battery exhibits a high energy density of $311.4 \mathrm{~W} \mathrm{~h} \mathrm{~kg}^{-1}$ at $3485 \mathrm{~W} \mathrm{~kg}^{-1}$ and long cycling life, indicating its potential as an advanced energy storage device.

\section{EXPERIMENTAL SECTION}

\section{Characterizations}

Series of characterizations were used to investigate the material properties. A Bruker AXS D8 Advance instrument $(\mathrm{Cu}-\mathrm{Ka}$ radiation, $1.5418 \AA$ ) was used to collect the X-ray diffraction (XRD) patterns of all samples. The morphological structure was detected using scanning electron microscopy (SEM; JSM-7500F) and transmission electron microscopy (TEM; Tecnai G2 F20). X-ray photoelectron spectroscopy (XPS) was performed on an EscaLab 250Xi to analyze the molecular structure and elemental valence states. The specific surface area and pore size distribution were tested by a Brunauer Emmett-Teller method using a surface area analyzer ASAP-2020.

\section{Synthesis of Se@C templates}

Carbon-coated selenium nanorods were prepared using a onestep hydrothermal method. $\mathrm{Na}_{2} \mathrm{SeO}_{3}(375 \mathrm{mg})$ and $150 \mathrm{mg}$ of sodium dodecyl sulfate (SDS) were dissolved in $60 \mathrm{~mL}$ of deionized water. Then $1.5 \mathrm{~g}$ of ascorbic acid was added into the asprepared mixed solution and stirred for $10 \mathrm{~min}$. After that, the red solution was transferred to a $100-\mathrm{mL}$ Teflon-lined autoclave, and was heated to $120^{\circ} \mathrm{C}$ for $24 \mathrm{~h}$ followed by $180^{\circ} \mathrm{C}$ for $6 \mathrm{~h}$. The obtained black Se@C nanorods were washed with deionized water and ethanol, collected by vacuum filtration, and dried in an oven at $60^{\circ} \mathrm{C}$.

\section{Synthesis of Se@C-Ni(OH $)_{2}$ and nickel selenides}

For the growth of Se@C-Ni(OH $)_{2}, 50 \mathrm{mg}$ of Se@C nanorods, $145 \mathrm{mg}$ of $\mathrm{Ni}\left(\mathrm{NO}_{3}\right)_{2} \cdot 6 \mathrm{H}_{2} \mathrm{O}, 35 \mathrm{mg}$ of methenamine, and $7.3 \mathrm{mg}$ of trisodium citrate dihydrate were added to a $100-\mathrm{mL}$ flask containing $40 \mathrm{~mL}$ of deionized water, and ultrasound treated for $30 \mathrm{~min}$. Then, the mixed solution was refluxed at $90^{\circ} \mathrm{C}$ for $6 \mathrm{~h}$. Finally, the product was washed with deionized water and ethanol, collected by vacuum filtration, and dried in the oven at $60^{\circ} \mathrm{C}$.

The nickel selenide was synthesized using the in situ selenylation process. Se@C-Ni(OH $)_{2}(50 \mathrm{mg})$ was placed in the tube furnace. With a heating rate of $5^{\circ} \mathrm{C} \mathrm{min}^{-1}$, the tube furnace was heated to different temperatures and kept for $2 \mathrm{~h}$ under $\mathrm{N}_{2}$ conditions. Cubic $\mathrm{NiSe}_{2}, \mathrm{NiSe}_{2} / \mathrm{Ni}_{0.85} \mathrm{Se}$, and hexagonal $\mathrm{Ni}_{0.85} \mathrm{Se}$ were prepared at the heating temperatures of 450, 500 and $550^{\circ} \mathrm{C}$, and termed as CNT@CNS, CNT@CHNS, and CNT@HNS, respectively.

\section{Electrochemical characterization}

All the electrochemical tests were conducted on a $\mathrm{CHI} 760 \mathrm{e}$ instrument. Ni foam, platinum gage, calomel electrode, and $6 \mathrm{~mol} \mathrm{~L}^{-1} \mathrm{KOH}$ were used as the current collector, counter electrode, reference electrode, and electrolyte solution, respec- tively. For the preparation of the working electrode, $32 \mathrm{mg}$ of the as-prepared materials, $4 \mathrm{mg}$ conductive carbon, and $80 \mu \mathrm{L} 5 \%$ polytetrafluoroethylene (PTFE; mass ratio, 8:1:1) were mixed to obtain a homogenous slurry. Then, $2.5 \mathrm{mg}$ of the mixture was painted on the Ni foam $(1 \mathrm{~cm} \times 1 \mathrm{~cm})$. With a frequency range of $0.01-10^{6} \mathrm{~Hz}$, electrochemical impedance spectroscopy (EIS) was tested for further analysis of the electrochemical mechanism.

\section{Calculation method}

According to the galvanostatic curves, the specific capacities $\left(C_{\mathrm{m}}\right.$, $\mathrm{Cg}^{-1}$ or $\mathrm{mA} \mathrm{h}^{-1}$ ) of the prepared samples were calculated using the following equation [34]:

$C_{\mathrm{m}}=\frac{\int_{0}^{t} I \mathrm{~d} t}{m}$,

where $m, t$, and $I$ are the mass loading (mg), discharge time (s), and discharge current $(\mathrm{mA})$, respectively. For an in-depth comprehension of the energy storage mechanism, the following formula was applied [35]:

$i=a v^{b}$.

In this formula, $i$ and $v$ are the peak current and scan rate. $a$ and $b$ are constants. This originates from Equation (3) [36]:

$i=i_{\text {EDLC }}+i_{\text {diff }}=k_{1} v+k_{2} v^{0.5}$,

where the $i_{\text {EDLC }}$ is the current of electrical double-layer capacitor (EDLC), $k_{1} v\left(i_{\mathrm{EDLC}}\right)$ and $k_{2} v^{0.5}$ ( $\left.i_{\text {diff }}\right)$ are the capacitive and diffusion-controlled current contributions. In the beginning, the fitting calculations were conducted in the whole cyclic voltammetry $(\mathrm{CV})$. However, the obtained strange shapes illustrate the inadequacy of this formula in the whole CV. This can be explained using the theory of Bard [23]:

$$
\begin{aligned}
i_{\text {diff }} & =k_{1} v^{1 / 2}=n F A_{\text {diff }} C_{0}\left(\pi D_{0} \sigma\right)^{1 / 2} \chi(\sigma t) \propto A_{\text {diff }} D_{0}^{1 / 2}, \\
\sigma & =n F v / R T, \\
i_{\text {EDLC }} & =k_{2} v=A_{\text {EDLC }} C_{\mathrm{d}} v \propto A_{\text {EDLC }},
\end{aligned}
$$

where $n, F$, and $A_{\text {diff }}$ represent the charge transfer number, Faradic constant, and electrochemical active area, respectively. $C_{0}, D_{0}$, and $\chi$ are the reagent concentration, reactant diffusion efficiency, and dimensionless number, respectively. $R$ is molar gas constant and $T$ is the temperature. $A_{\mathrm{EDLC}}$ and $C_{\mathrm{d}}$ are the area of double-layer and specific capacitance, respectively. The scan rate fluctuates slightly, the corresponding current changes, and it is appropriate to regard $\chi$ as constant. However, for the large range scan rate, it should not be regarded as a constant, otherwise resulting in false fitting results in whole CVs. Therefore, peak currents were applied to fitting to calculate $k_{1}$ and $k_{2}$.

The energy density $\left(E, \mathrm{Wh} \mathrm{kg}^{-1}\right)$ and power density $(P$, $\mathrm{W} \mathrm{kg}^{-1}$ ) of the $\mathrm{Zn} / / \mathrm{Ni}$ battery are given below [37]:

$E=C_{\mathrm{m}} \times \Delta V$,

$P=\frac{E}{\Delta t}$,

where $\Delta V$ and $\Delta t$ are the working potential and discharging time.

\section{RESULTS AND DISCUSSION}

Morphology and structure features

The overall synthesis routes of the CNT-supported nickel sele- 
nides are shown in Fig. 1a. Initially, using sodium selenite as the selenium source, ascorbic acid as a carbon source, and SDS as a surfactant, carbon-coated Se nanorods were synthesized using a one-step hydrothermal method. As shown in Fig. 1b and Fig. S1, the obtained Se@C presents a uniform nanorod shape with lengths of $5 \mu \mathrm{m}$ and widths of $400 \mathrm{~nm}$. In energy dispersive spectroscopy (EDS)-mapping images, a homogeneous distribution of carbon and selenium elements was observed on each nanorod, suggesting the carbon-coated feature. In addition, the prepared Se@C nanorods were employed as supports for the growth of $\mathrm{Ni}(\mathrm{OH})_{2}$ nanoflakes. Fig. 1c-e demonstrate the morphology characteristics of the Se@C-Ni(OH $)_{2}$ composites. Uniform $\mathrm{Ni}(\mathrm{OH})_{2}$ nanoflakes wrapping on the surface of the Se@C nanorods were achieved. The obtained Se@C-Ni(OH $)_{2}$ nanorods have larger wall-diameter and rough surfaces. As shown in Fig. S2, the EDS mapping of the composites illustrates the uniform distribution of $\mathrm{Ni}, \mathrm{C}$, Se, and $\mathrm{O}$ elements. The thermogravimetric analysis (TGA) tests of Se@C and Se@C$\mathrm{Ni}(\mathrm{OH})_{2}$ were conducted and displayed in Fig. S3. By calculations, the contents of $\mathrm{Se}$, carbon, and $\mathrm{Ni}(\mathrm{OH})_{2}$ are $70.4 \%, 11.6 \%$, and $17.9 \%$, respectively. The high Se content guarantees the complete transformation from $\mathrm{Ni}(\mathrm{OH})_{2}$ to nickel selenides.

The as-prepared Se@C-Ni(OH)$)_{2}$ nanorods (templates) were converted into nickel selenides after in situ thermal conversion. During this process, selenium inside the nanorod migrated to the outside during annealing and reacted with $\mathrm{Ni}(\mathrm{OH})_{2}$ nanoflakes, resulting in CNTs-supported nickel selenides. Due to the Kirkendall effects, selenium atoms diffuse through the carbon shell to react with $\mathrm{Ni}(\mathrm{OH})_{2}$, forming CNT@nickel selenides. The diffusion of selenium atoms through CNT contributes to abundant tunnels with a diameter around $1 \mathrm{~nm}$, as demonstrated by the $\mathrm{N}_{2}$ adsorption/desorption isotherms (Figs S4-S6). This in situ selenylation strategy is different from the previously reported studies. For the traditional strategy, the selenium vapor
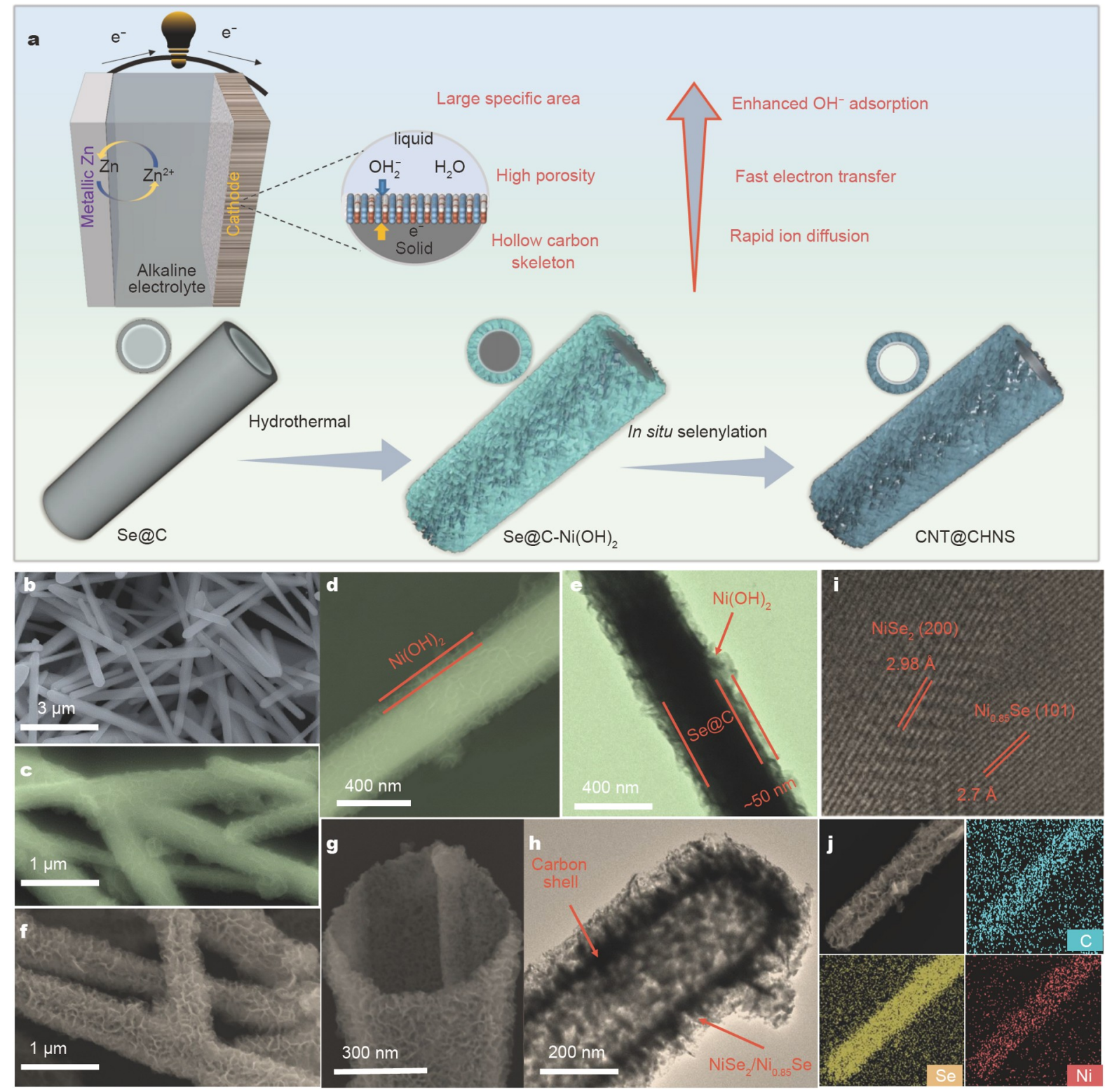

Figure 1 (a) Schematic of the prepared CNT-supported nickel selenides for aqueous Zn battery. (b) SEM image of Se@C nanorods; (c-e) SEM and TEM images of Se@C-Ni(OH) $2 ;(f-j)$ SEM, TEM, and EDS mapping images of CNT@CHNS. 
as the selenium source will react with transition metal oxide (or hydroxide) [38]. It is difficult to ensure a homogeneous reaction environment; however, the in situ selenylation strategy addresses the issue. In addition, the construction of uniform-sized nanopores within the CNT using the in situ selenylation is a remarkable advancement.

A temperature-dependent phase transition phenomenon from cubic $\mathrm{NiSe}_{2} \rightarrow \mathrm{NiSe}_{2} / \mathrm{Ni}_{0.85} \mathrm{Se} \rightarrow$ hexagonal $\mathrm{Ni}_{0.85} \mathrm{Se}$ was detected. The related chemical reactions are as follows:

$$
\begin{aligned}
& \mathrm{Ni}(\mathrm{OH})_{2}+\mathrm{Se} \rightarrow \mathrm{NiSe}_{2}+\mathrm{SeO}_{x} \uparrow+\mathrm{H}_{2} \mathrm{O} \uparrow, \\
& \mathrm{NiSe}_{2} \rightarrow \mathrm{Ni}_{0.85} \mathrm{Se}+\mathrm{Se} \uparrow .
\end{aligned}
$$

The result of the TGA/differential scanning calorimetry (DSC) in Fig. S7 demonstrates the phase transformation in nickel selenides. Two weight-loss steps in the TGA plot of cubic $\mathrm{NiSe}_{2}$, associated with the two endothermic peaks in the DSC plot, result from the $\mathrm{NiSe}_{2}-\mathrm{Ni}_{0.85} \mathrm{Se}$ and $\mathrm{Ni}_{0.85}-\mathrm{NiSe}$ transformations, respectively. As shown in Fig. S8 and Fig. 1f-i, SEM and TEM images of CNT@CNS,CNT@CHNS, and CNT@HNS reveal hollow carbon-supported nickel selenide morphology characteristics. For the CNT@CNS obtained at the annealing temperature of $450^{\circ} \mathrm{C}$, the outer cubic $\mathrm{NiSe}_{2}$ presents porous nanoflake features (Fig. S8a, d). When the annealing temperature reached $500^{\circ} \mathrm{C}, \mathrm{CNT} @ \mathrm{CHNS}$ preserves similar morphology with CNT@CNS, and exterior $\mathrm{NiSe}_{2} / \mathrm{Ni}_{0.85} \mathrm{Se}$ composites have loose and porous characteristics (Fig. 1h). As shown in Fig. 1i, the measured fringe spacings of 2.70 and $2.98 \AA$ are ascribed to the $\mathrm{Ni}_{0.85} \mathrm{Se}$ (101) and $\mathrm{NiSe}_{2}$ (200), respectively. Moreover, the uniform distribution of $\mathrm{C}, \mathrm{Ni}$, and Se was observed (Fig. 1j). As selenization temperature rises to $550^{\circ} \mathrm{C}$, due to the complete phase transformation from cubic $\mathrm{NiSe}_{2}$ to hexagonal $\mathrm{Ni}_{0.85} \mathrm{Se}$ and evaporation of Se, the outer nickel selenides show distinct volume shrinkage, transforming from nanoflakes to nanoparticles (Fig. S8c, f). However, it seems that such morphology transformation is detrimental to the pore structure. The nitrogen adsorption/desorption isotherms shown in Figs S4-S6 reveal the decreased specific surface area at higher annealing temperatures. All samples show distinct $\mathrm{H}_{1}$-type adsorption/desorption isotherm and similar pore size distribution. The nanopores with a diameter around $1 \mathrm{~nm}$ are within the CNT due to selenium atom diffusion, and the mesopores with diameters of $20-80 \mathrm{~nm}$ are formed in the intercrystal pores of the nickel selenide crystals. According to the calculations, the specific surface areas of CNT@CNS,CNT@CHNS, and CNT@HNS are 145, 140, and $127 \mathrm{~cm}^{3} \mathrm{~g}^{-1}$, respectively. The nanopore volumes within different samples are similar, whereas the mesoporous volumes decrease with temperature; it is associated with the crystallization of the nickel selenides at higher annealing temperatures, as evidenced by the SEM images showing the transformation from nanoflakes to nanospheres of nickel selenides on CNT.

Fig. 2a demonstrates the phase transformation within the prepared samples. As shown in Fig. 2b, the XRD patterns of all samples show strong diffraction peaks, suggesting high crystallinity. For Se@C nanorods, the diffraction peaks at $23.5^{\circ}, 29.7^{\circ}$, $41.4^{\circ}, 43.6^{\circ}$, and $45.4^{\circ}$ are related to (100), (101), (110), (012), and (111) planes of hexagonal Se (JCPDS: 06-0362), respectively. After the coating of $\mathrm{Ni}(\mathrm{OH})_{2}$ nanoflakes, no new diffraction peaks were found in $\mathrm{Se} @ \mathrm{C}-\mathrm{Ni}(\mathrm{OH})_{2}$, demonstrating the amorphous feature of $\mathrm{Ni}(\mathrm{OH})_{2}$. For CNT@CNS, CNT@CHNS, and CNT@HNS, the diffraction peaks of $30.0^{\circ}, 33.6^{\circ}$, and $36.9^{\circ}$ are ascribed to (200), (210), and (211) planes of cubic $\mathrm{NiSe}_{2}$ (JCPDS: 41-1495), respectively; the other major peaks, located at $33.2^{\circ}$, $44.9^{\circ}$, and $50.7^{\circ}$ are attributed to (101), (102), and (110) planes of hexagonal $\mathrm{Ni}_{0.85} \mathrm{Se}$ (JCPDS: 18-0888), respectively. No other impurities were observed. Fig. S9 shows the EDS of CNT@CHNS, and based on the calculations, the contents (wt\%) of $\mathrm{NiSe}_{2}$ and $\mathrm{Ni}_{0.85} \mathrm{Se}$ in the composites are $27.05 \%$ and $35.31 \%$. For a better understanding of the in situ selenylation process, XPS was conducted to investigate the surface chemical state changes, as displayed in Fig. 2c-f and Fig. S10. The peaks of $\mathrm{C}$, $\mathrm{O}, \mathrm{Se}$, and $\mathrm{Ni}$ are all observed in full spectra (Fig. 2c). In the high-resolution $\mathrm{Ni} 2 \mathrm{p}$ spectrum (Fig. 2d), the characteristic peaks of Se@C-Ni(OH) $)_{2}$ at 875.0 and 856.9 are ascribed to $\mathrm{Ni} 2 \mathrm{p}_{1 / 2}$ and $\mathrm{Ni} 2 \mathrm{p}_{3 / 2}$, respectively, from the $\mathrm{Ni}-\mathrm{O}$ bond. After the in situ selenylation process, the new characteristic peaks located at 871.7 and $853.7 \mathrm{eV}$ are attributed to $\mathrm{Ni} 2 \mathrm{p}_{1 / 2}$ and $\mathrm{Ni}$ $2 \mathrm{p}_{3 / 2}$, respectively, from the $\mathrm{Ni}-\mathrm{Se}$ bond (Fig. $2 \mathrm{~d}$ ). In addition, the high-resolution Se 3d spectra were observed. For Se@C$\mathrm{Ni}(\mathrm{OH})_{2}$, due to the coverage of $\mathrm{Ni}(\mathrm{OH})_{2}$ and carbon, the electrons of Se could hardly get out of the inside (Fig. 2e). The Se 3d of CNT@CHNS has three origins: $\mathrm{SeO}_{x}(59.1 \mathrm{eV})$, Se $3 \mathrm{~d}_{5 / 2}$ $(54.7 \mathrm{eV})$, and Se $3 \mathrm{~d}_{3 / 2}(55.9 \mathrm{eV})$. Fig. $2 \mathrm{f}$ shows the high-resolution $\mathrm{C} 1 \mathrm{~s}$ spectra. The characteristic peaks at 284.7 and $287.5 \mathrm{eV}$ are ascribed to $\mathrm{C}-\mathrm{C}$ and $\mathrm{C}-\mathrm{O}$ bonds, respectively. All the characterizations illustrate the in situ selenylation process. Considering the large specific surface area, high porosity, and unique tubular structure, CNT@CHNS can serve as a highperformance electrode material.

\section{Electrochemical analysis}

A typical three-electrode system was used to investigate the electrochemical performance of all samples. Before the full performance testing, an electrochemical activation process was conducted at $25 \mathrm{mV} \mathrm{s}^{-1}$ for 20 cycles. After full activation, a series of electrochemical tests were conducted, including $\mathrm{CV}$, galvanostatic charge-discharge (GCD), and EIS. Fig. 3a and Fig. S11 display the CV curves of Se@C-Ni(OH), CNT@CNS, CNT@CHNS, and CNT@HNS. The CNT@CHNS has a higher oxidation/reduction peak current, indicating more redox reactions and better performance than its counterparts. In addition, redox peaks change with the increasing scan rates. At a high scan rate of $50 \mathrm{mV} \mathrm{s}^{-1}, \mathrm{CNT} @ \mathrm{CHNS}$ presents a pair of symmetric redox peaks, suggesting the excellent reversibility of Faradic reactions and high Coulombic efficiency. Corresponding to $\mathrm{CV}$ curves, a pair of symmetrical potential platforms were acquired in GCD curves (Fig. 3b). According to the calculations, at a current density of $2 \mathrm{Ag}^{-1}$, the specific capacities of Se@C$\mathrm{Ni}(\mathrm{OH})_{2}, \mathrm{CNT} @ \mathrm{CNS}, \mathrm{CNT} @ \mathrm{CHNS}$, and CNT@HNS are 304, 324, 616, and $498 \mathrm{Cg}^{-1}$, respectively (Fig. 3c). For CNT@CHNS, as the current density rises to $20 \mathrm{~A} \mathrm{~g}^{-1}$, a high specific capacity of $524 \mathrm{C} \mathrm{g}^{-1}$ is achieved, indicating the excellent rate capability. Moreover, nearly $100 \%$ Coulombic efficiency is acquired. In addition, cycling tests were conducted at $5 \mathrm{~A} \mathrm{~g}^{-1}$ and displayed in Fig. 3d. After 3000 cycles, Se@C-Ni(OH) 2 , CNT@CNS, CNT@CHNS, and CNT@HNS exhibit 68\%,78\%,80\%, and 82\% capacity retentions, respectively. As shown in Fig. S12, the hollow rod morphology was still observed after cycling. Fig. 3e presents an overall electrochemical performance comparison. The CNT@CHNS shows higher specific capacity, better rate capability, and more stable cycling life than its counterparts.

In addition, the EIS was tested. As shown in Fig. 3f, the 

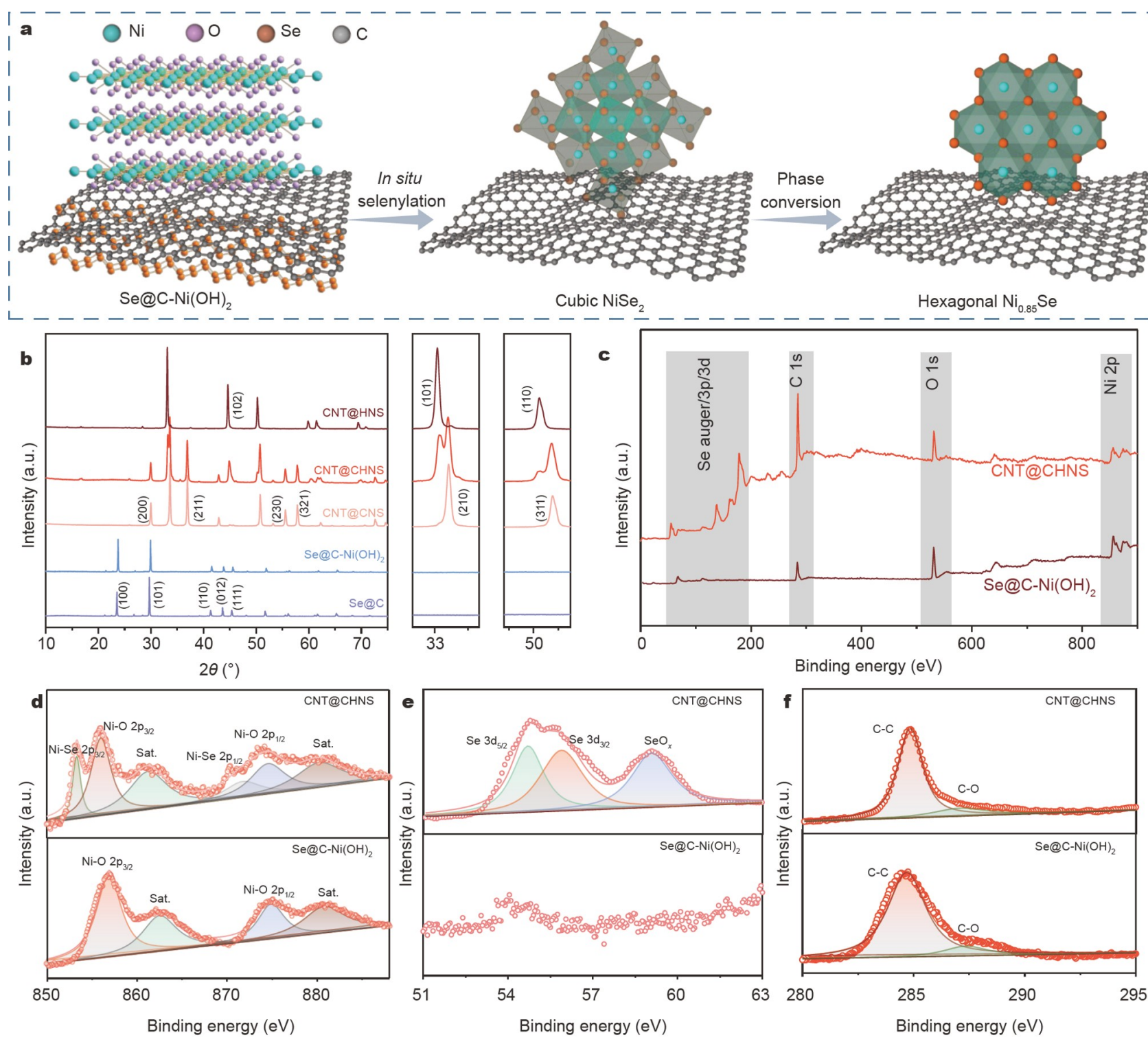

Figure 2 (a) Crystal-structural transformation of hexagonal $\mathrm{Ni}(\mathrm{OH})_{2}$, cubic $\mathrm{NiSe}_{2}$, and hexagonal $\mathrm{Ni}_{0.85} \mathrm{Se}$. (b) XRD patterns of the prepared samples; (c) XPS; (d-f) Ni 2p, Se 3d, C 1s of CNT@CHNS and Se@C-Ni(OH)2.

impedance spectrum presents a compressed semicircle feature and a sloping line at high- and low-frequency regions, respectively. In addition, the impedance spectrum fitting was conducted and displayed in Table S1. CPE, $R_{\mathrm{s}}, R_{\mathrm{ct}}$, and $W_{\mathrm{o}}$ represent the constant phase element, electrolyte resistance, chargetransfer resistance, and Warburg element (open), respectively; $W_{\mathrm{o}}-R$ is related to the ion diffusion capability of the electrode. The CNT@CHNS exhibits lower $R_{\mathrm{ct}}$ and $W_{\mathrm{o}}-R$, illustrating easier electron transfer and rapid electrolyte diffusion. Therefore, CNT@CHNS will present faster redox kinetics, higher specific capacity, and better rate capability.

For an in-depth comprehension of the energy storage mechanism, Equations (2) and (3) were applied. For a traditional capacitive process, $b$ is equal to 1 ; for a semi-infinite diffusion behavior, $b$ is 0.5 . In this study, the calculated $b$ values of Se@C$\mathrm{Ni}(\mathrm{OH})_{2}$, CNT@CNS, CNT@CHNS, and CNT@HNS are 0.63, $0.59,0.54$, and 0.60 , respectively (Fig. $3 \mathrm{~g}$ ), all close to 0.5 , indicating the typical diffusion-controlled behavior related to Fara- dic reactions during charge-discharge.

In the beginning, the fitting was conducted, and results are displayed in Fig. S13. Such a strange shape suggests the unsuitability in whole CV fitting. This issue has been discussed in our previous study [39]. Therefore, peak currents were used for fitting instead of whole CVs. The fitting results are displayed in Fig. $3 \mathrm{~h}$ and Fig. S14; $k_{1}$ and $k_{2}$ were calculated to identify $k_{1} v$ and $k_{2} v^{0.5}$ values, i.e., capacitive and diffusion-controlled current contributions at different scan rates. At the scan rate of $25 \mathrm{mV} \mathrm{s}^{-1}$, the diffusion contributions of $\mathrm{Se} @ \mathrm{C}-\mathrm{Ni}(\mathrm{OH})_{2}$, CNT@CNS,CNT@CHNS, and CNT@HNS are 77.2\%,77.6\%, $90.8 \%$ and $78.0 \%$, respectively. Moreover, as shown in Table S2, the $k_{2} v^{0.5}$ of CNT@CHNS is higher than others, illustrating that more redox reactions occurred during the charging-discharging process.

\section{Electrochemical activation mechanisms of CNT@CHNS}

Considering the aforementioned typical redox reactions that 

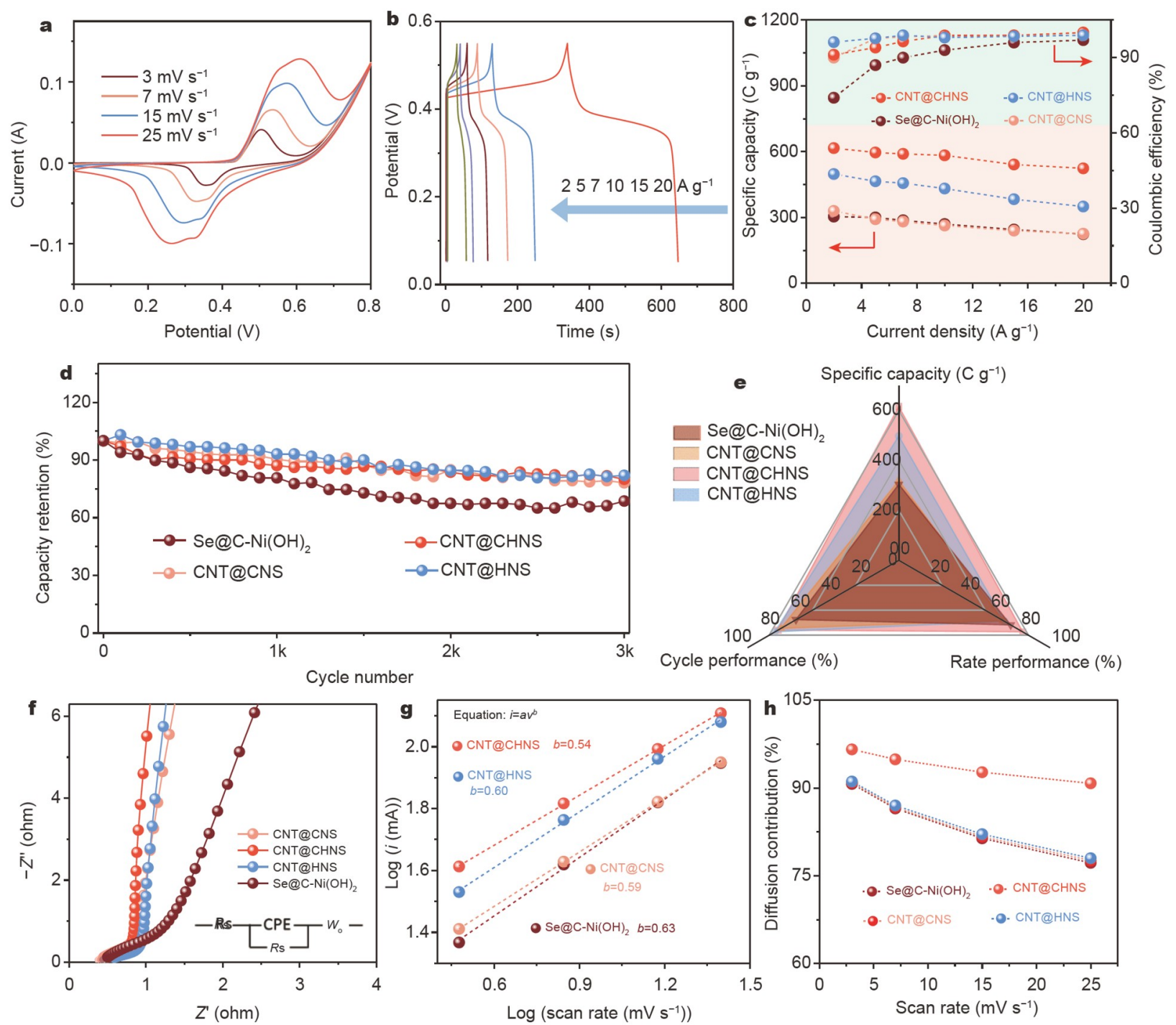

Figure 3 (a) CV and (b) GCD curves of CNT@CHNS; (c) the specific capacity and Coulombic efficiency at different current densities; (d) cycling performance; (e) performance comparison; (f) EIS tests; (g) the calculated $b$ value; (h) diffusion contribution at different scan rates.

occurred during charging-discharging, it is essential to figure out the stable charging-discharging product. As shown in Fig. 4a, presenting the CV cycles of CNT@CHNS, dramatic changes between the initial and subsequent CVs were observed. We speculate that this is attributed to the occurrence of irreversible phase conversion, i.e., the formation of a hydroxy-like structure on the surface [40]. To clarify this, a series of ex situ characterizations were conducted. Fig. $4 \mathrm{~b}$ shows the XRD patterns of CNT@CHNS at different times during the activation process. The broad diffraction peak at $23.9^{\circ}$ was from the carbon cloth substrate. After five cycles, the diffraction peaks still show strong intensities similar to the initial state. The diffraction peaks at $30.0^{\circ}, 36.9^{\circ}, 44.9^{\circ}$, and $50.7^{\circ}$ are for $\mathrm{NiSe}_{2}$ (200), $\mathrm{NiSe}_{2}(211)$, $\mathrm{Ni}_{0.85} \mathrm{Se}$ (102), and $\mathrm{Ni}_{0.85} \mathrm{Se}$ (110), respectively. The intensity of peaks decreased as the activation process proceeded. After 20 cycles of complete activation, all diffraction peaks are visible, indicating the permanent existence of $\mathrm{NiSe}_{2}$ and $\mathrm{Ni}_{0.85} \mathrm{Se}$. However, no diffraction peaks of the new phase were found, probably due to low crystallinity. XPS was applied to investigate the surface chemical-state changes in electrochemical activation.
As shown in Fig. S15, the peaks of Se, C, O, and $\mathrm{Ni}$ were observed. Moreover, due to the PTFE binder, F 1s was observed. Fig. $4 \mathrm{c}$ is the high-resolution $\mathrm{Ni} 2 \mathrm{p}$ after full activation. The characteristic peaks of 856.3 and $873.9 \mathrm{eV}$ are ascribed to $\mathrm{Ni} 2 \mathrm{p}_{3 / 2}$ and $\mathrm{Ni} 2 \mathrm{p}_{1 / 2}$, respectively, from the $\mathrm{Ni}-\mathrm{O}$ bond. In addition, the signal peaks of Se 3d were observed. In high-resolution Se 3d, the characteristic peaks of 56.5 and $59.1 \mathrm{eV}$ are assigned to Se $3 \mathrm{~d}_{5 / 2}$ and Se $3 \mathrm{~d}_{3 / 2}$, respectively (Fig. $4 \mathrm{~d}$ ). The high-resolution TEM image in Fig. 4e illustrates the hydroxyl-like structure of CNT@CHNS after full activation; instead of regularly striated crystal faces in Fig. 1i, it presents some unordered stripes. The measured lattice fringes of $0.271,0.240$, and $0.270 \mathrm{~nm}$ are ascribed to $\mathrm{Ni}(\mathrm{OH})_{2}(100), \mathrm{NiSe}_{2}$ (211), and $\mathrm{Ni}_{0.85} \mathrm{Se}$ (101), respectively. Moreover, the top-view of hexagonal $\mathrm{Ni}(\mathrm{OH})_{2}$ (100) was observed. Based on these facts, it is rational to conclude that hexagonal $\mathrm{Ni}(\mathrm{OH})_{2}$ (JCPDS: 14-0117), with high electrochemical activity, formed on the surface after electrochemical activation. During the electrochemically induced reconstruction process, $\mathrm{OH}^{-}$will substitute selenium on the surface and coordinate with the exposed nickel to form hex- 

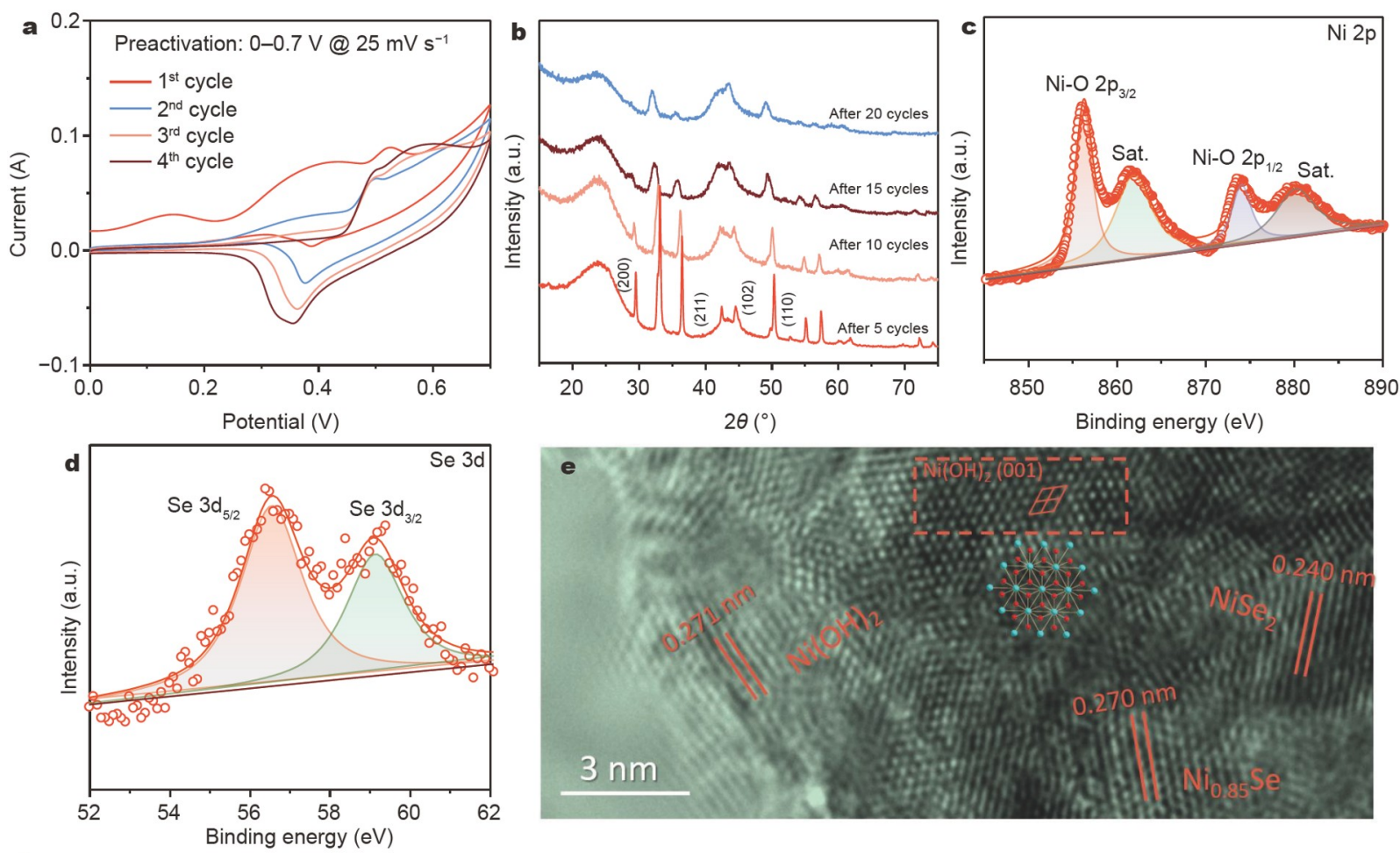

f
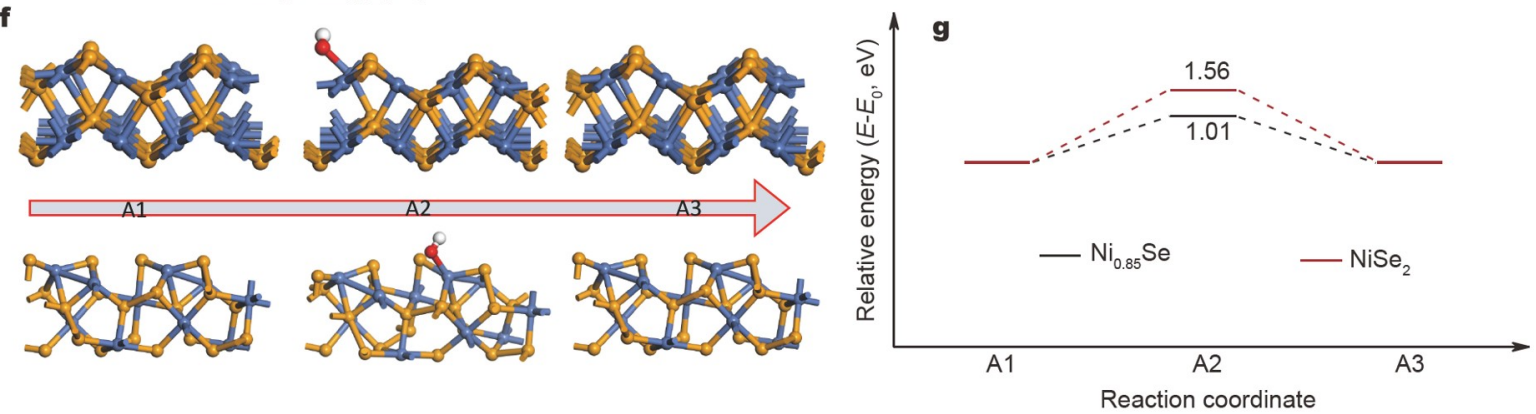

Figure 4 Characterizations of CNT@CHNS during activation. (a) CV changes; (b) XRD patterns. (c, d) Ni 2p and Se 3d after full activation. (e) Highresolution TEM images. (f, g) The calculated energy difference of $\mathrm{OH}^{-}$adsorbed/desorbed on $\mathrm{Ni}_{0.85} \mathrm{Se}_{\text {and }} \mathrm{NiSe}_{2}$.

agonal nickel hydroxide [41-43].

Considering the distinct performance differences between CNT@CNS and CNT@HNS, we propose that the formation of the electrochemical active hydroxy-like structures on hexagonal $\mathrm{Ni}_{0.85} \mathrm{Se}$ is kinetically faster than cubic $\mathrm{NiSe}_{2}$. Here, density functional theory (DFT) calculations were employed to calculate the Gibbs free energy $(\Delta G)$ of $\mathrm{OH}^{-}$adsorbing on nickel-selenide surfaces, and the smaller $\Delta G$ indicates the kinetically faster reaction. As shown in Fig. 4f, the models built for the calculation are $\mathrm{NiSe}_{2}(210)$ and $\mathrm{Ni}_{0.85} \mathrm{Se}$ (101), according to the high diffraction intensity in XRD patterns. Fig. $4 \mathrm{~g}$ is the calculated energy difference of $\mathrm{OH}^{-}$adsorbed/desorbed on $\mathrm{Ni}_{0.85} \mathrm{Se}$ and $\mathrm{NiSe}_{2}$. For $\mathrm{Ni}_{0.85} \mathrm{Se}$, the energy barrier of $\mathrm{OH}^{-}$adsorption is $1.01 \mathrm{eV}$, lower than $1.56 \mathrm{eV}$ of $\mathrm{NiSe}_{2}$. Therefore, compared with cubic $\mathrm{NiSe}_{2}, \mathrm{OH}^{-}$easily reacts with hexagonal $\mathrm{Ni}_{0.85} \mathrm{Se}$, indicating the kinetically faster formation of the hydroxyl-like structure at the interface, which contributes to the better electrochemical performance of CNT@HNS and CNT@CHNS. However, limited by the reduced specific surface area and destructed mesoporous structure due to the over-crystallization of $\mathrm{Ni}_{0.85} \mathrm{Se}$, CNT@CHNS exhibits superior energy storage capability than CNT@HNS.
The excellent electrochemical performance of CNT@CHNS is ascribed to the following merits: its hollow structure and electrolyte reservoir ensure a high touchable surface area; the large specific surface area and rich pore structure guarantee fast electrolyte ion diffusion and transportation; the carbon skeleton and unique $\mathrm{NiSe}_{2} / \mathrm{Ni}_{0.85} \mathrm{Se}$ heterostructure are conducive for charge transfer and intensify electronic conductivity. Thus, CNT@CHNS presents a high specific capacity of $616 \mathrm{Cg}^{-1}$, excellent rate capability, and stable cycling performance.

\section{Aqueous CNT@CHNS//Zn battery}

To explore the practical application of CNT@CHNS, an aqueous $\mathrm{Ni} / / \mathrm{Zn}$ battery was assembled using $\mathrm{Zn}$ plate as the anode, CNT@CHNS as the cathode, and KOH/ZnAc mixed solution as the electrolyte. The $\mathrm{CV}$ curves of the $\mathrm{Ni} / / \mathrm{Zn}$ battery are in a potential range of $1.4-2.2 \mathrm{~V}$ (Fig. $5 \mathrm{~b}$ ). At a scan rate of $5 \mathrm{mV} \mathrm{s}^{-1}$, a pair of symmetric redox peaks are between 1.91 and $1.65 \mathrm{~V}$. As the scan rate increases, the redox peaks shift. Even at $50 \mathrm{mV} \mathrm{s}^{-1}$, symmetric redox peaks are observed, suggesting the superior reversibility of the Ni//Zn battery. Fig. $5 b$ depicts the GCD curves within $1.4-1.95 \mathrm{~V}$. Corresponding to $\mathrm{CV}$ curves, flat 

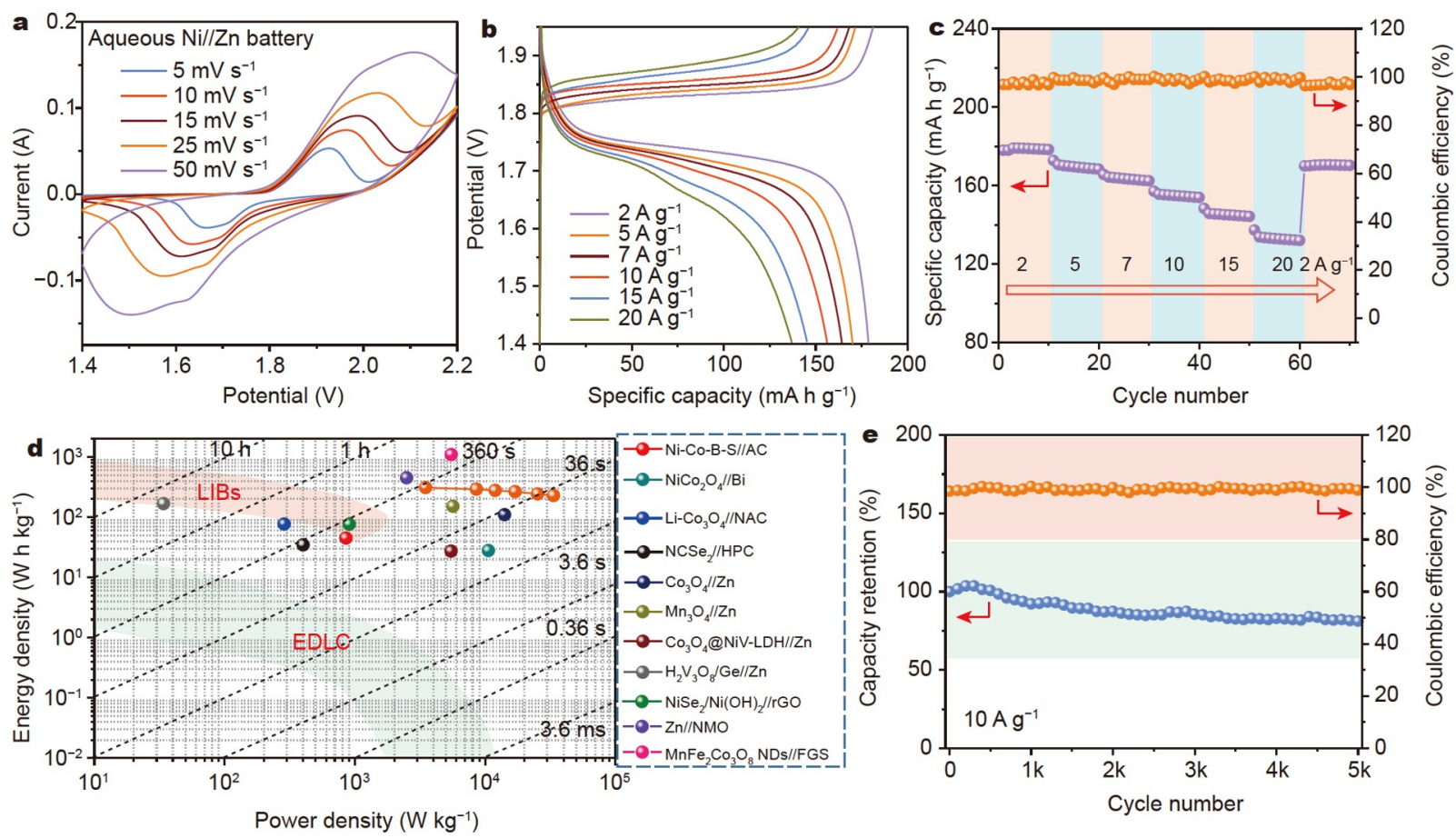

Figure 5 (a) CV and (b) GCD curves of the assembled Ni//Zn battery; (c) rate capability and Coulombic efficiency; (d) Ragone plot; (e) cycle performance.

potential platforms are acquired in GCD curves. At a current density of $2 \mathrm{~A} \mathrm{~g}^{-1}$, the charging and discharging voltage platform is located between 1.74 and $1.83 \mathrm{~V}$. In addition, the rate capability and Coulombic efficiency of the $\mathrm{Ni} / / \mathrm{Zn}$ battery were investigated and displayed in Fig. 5c. At scan rates of 2, 5, 7, 10, 15 , and $20 \mathrm{~A} \mathrm{~g}^{-1}$, the specific capacities of the $\mathrm{Ni} / / \mathrm{Zn}$ battery are $179,169,163,154,145$, and $133 \mathrm{~mA} \mathrm{~h}^{-1}$, respectively. When the current density returned to $2 \mathrm{Ag}^{-1}$, a high specific capacity of $171 \mathrm{~mA} \mathrm{hg}^{-1}$ was acquired, indicating the excellent rate capability. Moreover, nearly $100 \%$ Coulombic efficiency is maintained.

Energy and power densities are vital parameters to evaluate the overall properties of energy storage devices. As shown in Fig. $5 \mathrm{~d}$, according to the calculations, the $\mathrm{Ni} / / \mathrm{Zn}$ battery exhibits a high energy density of $311.4 \mathrm{~W} \mathrm{~h} \mathrm{~kg}^{-1}$ at $3485 \mathrm{~W} \mathrm{~kg}^{-1}$, which is superior to recently reported results, such as $\mathrm{Ni}-\mathrm{Co}-\mathrm{B}-\mathrm{S} / / \mathrm{AC}$ [44], $\mathrm{NiCo}_{2} \mathrm{O}_{4} / / \mathrm{Bi}$ [45], $\mathrm{LiCo}_{3} \mathrm{O}_{4} / / \mathrm{NAC}$ [46], $\mathrm{NCSe}_{2} / / \mathrm{HPC}$ [47], $\mathrm{Co}_{3} \mathrm{O}_{4} / / \mathrm{Zn}$ [48], $\mathrm{Mn}_{3} \mathrm{O}_{4} / / \mathrm{Zn}$ [49], $\mathrm{Co}_{3} \mathrm{O}_{4} / \mathrm{NIV}-\mathrm{LDH} / / \mathrm{Zn}$ [50], $\mathrm{H}_{2} \mathrm{~V}_{3} \mathrm{O}_{8} / \mathrm{Ge} / / \mathrm{Zn}$ [51], $\mathrm{NiSe}_{2} / \mathrm{Ni}(\mathrm{OH})_{2} / / \mathrm{rGO}$ [38], $\mathrm{Zn} / / \mathrm{MNO}$ [52], and $\mathrm{MnFe}_{2} \mathrm{Co}_{3} \mathrm{O}_{8}$ NDs//FGS [53]. Moreover, at $10 \mathrm{Ag}^{-1}$ long cycling tests, $75 \%$ initial capacity retention is achieved after 5000 cycles (Fig. 5e). For these merits, the fabricated $\mathrm{Ni} / / \mathrm{Zn}$ battery is a potential high-performance energy storage device.

\section{CONCLUSIONS}

In conclusion, using the Se@C nanorod-templating strategy, hollow carbon-supported nickel selenide composites were synthesized through an in situ selenylation process for the first time. Due to the Kirkendall effect, selenium diffusion contributes to the nanopores within CNT, and a phase regulation strategy is used to form remarkable electrochemical active interfaces. The optimized CNT@HCNS electrode is achieved, which presents superior electrochemical performance, including a high specific capacity of $616 \mathrm{Cg}^{-1}$, excellent rate capability, and stable cycling life, compared with its counterpart. A series of ex situ characterizations and DFT calculations were applied to demonstrate the kinetically fast formation of an active hydroxy-structure at the electrode/electrolyte interfaces. The as-fabricated aqueous $\mathrm{Ni} / / \mathrm{Zn}$ battery exhibits an ultrahigh energy density of $311.4 \mathrm{~W} \mathrm{~h} \mathrm{~kg}^{-1}$ at $3485 \mathrm{~W} \mathrm{~kg}^{-1}$ and long cycling life. Therefore, our study proposes an in situ selenylation strategy for preparing carbon-supported nickel selenide composite electrodes and provides a method for phase regulation of nickel selenides to achieve higher electrochemical storage.

Received 17 June 2021; accepted 7 September 2021; published online 27 October 2021

1 Chao D, Zhou W, Xie F, et al. Roadmap for advanced aqueous batteries: From design of materials to applications. Sci Adv, 2020, 6: eaba4098

2 Chu S, Majumdar A. Opportunities and challenges for a sustainable energy future. Nature, 2012, 488: 294-303

3 Dunn B, Kamath H, Tarascon JM. Electrical energy storage for the grid: A battery of choices. Science, 2011, 334: 928-935

4 Cao Y, Li M, Lu J, et al. Bridging the academic and industrial metrics for next-generation practical batteries. Nat Nanotechnol, 2019, 14: 200207

5 Chao D, Fan HJ. Intercalation pseudocapacitive behavior powers aqueous batteries. Chem, 2019, 5: 1359-1361

6 Chen B, Chao D, Liu E, et al. Transition metal dichalcogenides for alkali metal ion batteries: Engineering strategies at the atomic level. Energy Environ Sci, 2020, 13: 1096-1131

7 Shi Y, Chen Y, Shi L, et al. An overview and future perspectives of rechargeable zinc batteries. Small, 2020, 16: 2000730

8 Zhang T, Yang C, Sun S, et al. Mesoporous $\mathrm{Fe}_{3} \mathrm{O}_{4} @ \mathrm{C}$ nanoarrays as high-performance anode for rechargeable $\mathrm{Ni} / \mathrm{Fe}$ battery. Sci China Mater, 2021, 64: 1105-1113

9 Yi Z, Chen G, Hou F, et al. Strategies for the stabilization of Zn metal anodes for Zn-ion batteries. Adv Energy Mater, 2021, 11: 2003065

10 Song $\mathrm{M}$, Tan $\mathrm{H}$, Chao $\mathrm{D}$, et al. Recent advances in $\mathrm{Zn}$-ion batteries. Adv Funct Mater, 2018, 28: 1802564 
11 Li H, Ma L, Han C, et al. Advanced rechargeable zinc-based batteries: Recent progress and future perspectives. Nano Energy, 2019, 62: 550587

12 Li C, Zhang Q, Li T, et al. Nickel metal-organic framework nanosheets as novel binder-free cathode for advanced fibrous aqueous rechargeable Ni-Zn battery. J Mater Chem A, 2020, 8: 3262-3269

13 Li C, Zhang Q, Sun J, et al. High-performance quasi-solid-state flexible aqueous rechargeable $\mathrm{Ag}$ - $\mathrm{Zn}$ battery based on metal-organic framework-derived Ag nanowires. ACS Energy Lett, 2018, 3: 2761-2768

14 He W, Wang S, Shao Y, et al. Water invoking interface corrosion: An energy density booster for Ni//Zn battery. Adv Energy Mater, 2021, 11: 2003268

15 Xiao $\mathrm{P}$, Xue L, Guo Y, et al. On-site building of a $\mathrm{Zn}^{2+}$-conductive interfacial layer via short-circuit energization for stable $\mathrm{Zn}$ anode. Sci Bull, 2021, 66: 545-552

16 Li H, Firby CJ, Elezzabi AY. Rechargeable aqueous hybrid $\mathrm{Zn}^{2+} / \mathrm{Al}^{3+}$ electrochromic batteries. Joule, 2019, 3: 2268-2278

$17 \mathrm{Xu} \mathrm{W}$, Wang Y. Recent progress on zinc-ion rechargeable batteries. Nano-Micro Lett, 2019, 11: 90

18 Chen Q, Jin J, Kou Z, et al. $\mathrm{Zn}^{2+}$ pre-intercalation stabilizes the tunnel structure of $\mathrm{MnO}_{2}$ nanowires and enables zinc-ion hybrid supercapacitor of battery-level energy density. Small, 2020, 16: 2000091

19 Li X, Tang Y, Zhu J, et al. Boosting the cycling stability of aqueous flexible $\mathrm{Zn}$ batteries via $\mathrm{F}$ doping in nickel-cobalt carbonate hydroxide cathode. Small, 2020, 16: 2001935

20 Shang W, Yu W, Liu Y, et al. Rechargeable alkaline zinc batteries: Progress and challenges. Energy Storage Mater, 2020, 31: 44-57

21 Liu W, Chen Y, Wang Y, et al. Influence of anion substitution on 3Darchitectured Ni-Co-A $(\mathrm{A}=\mathrm{H}, \mathrm{O}, \mathrm{P})$ as efficient cathode materials towards rechargeable Zn-based battery. Energy Storage Mater, 2021, 37: 336-344

22 Zhu X, Wu Y, Lu Y, et al. Aluminum-doping-based method for the improvement of the cycle life of cobalt-nickel hydroxides for nickelzinc batteries. J Colloid Interface Sci, 2021, 587: 693-702

23 Mei H, Zhang L, Zhang K, et al. Conversion of MOF into carboncoated $\mathrm{NiSe}_{2}$ yolk-shell microspheres as advanced battery-type electrodes. Electrochim Acta, 2020, 357: 136866

24 Wang T, Gao D, Xiao W, et al. Transition-metal-doped $\mathrm{NiSe}_{2}$ nanosheets towards efficient hydrogen evolution reactions. Nano Res, 2018, 11: 6051-6061

25 Lu C, Li Z, Xia Z, et al. Confining MOF-derived SnSe nanoplatelets in nitrogen-doped graphene cages via direct CVD for durable sodium ion storage. Nano Res, 2019, 12: 3051-3058

26 Mei H, Mei Y, Zhang S, et al. Bimetallic-MOF derived accordion-like ternary composite for high-performance supercapacitors. Inorg Chem, 2018, 57: 10953-10960

27 Zhou W, He J, Zhu D, et al. Hierarchical $\mathrm{NiSe}_{2}$ nanosheet arrays as a robust cathode toward superdurable and ultrafast $\mathrm{Ni}-\mathrm{Zn}$ aqueous batteries. ACS Appl Mater Interfaces, 2020, 12: 34931-34940

28 Xu B, Zhang $\mathrm{H}$, Mei $\mathrm{H}$, et al. Recent progress in metal-organic framework-based supercapacitor electrode materials. Coord Chem Rev, 2020, 420: 213438

29 Zheng Y, Tian Y, Sarwar S, et al. Carbon nanotubes decorated $\mathrm{NiSe}_{2}$ nanosheets for high-performance supercapacitors. J Power Sources, 2020, 452: 227793

30 Hao T, Liu Y, Liu G, et al. Insight into Faradaic mechanism of polyaniline@NiSe $\mathrm{N}_{2}$ core-shell nanotubes in high-performance supercapacitors. Energy Storage Mater, 2019, 23: 225-232

31 Zhang $\mathrm{H}, \mathrm{Xu} \mathrm{B}, \mathrm{Mei} \mathrm{H}$, et al. "HOT" alkaline hydrolysis of amorphous MOF microspheres to produce ultrastable bimetal hydroxide electrode with boosted cycling stability. Small, 2019, 15: 1904663

32 Zhang X, Wang H, Shui L, et al. Ultrathin $\mathrm{Ni}(\mathrm{OH})_{2}$ layer coupling with graphene for fast electron/ion transport in supercapacitor. Sci China Mater, 2021, 64: 339-348

33 Chen F, Cui X, Liu C, et al. $\mathrm{NiS} / \mathrm{Ni}_{3} \mathrm{~S}_{2} @ \mathrm{NiWO}_{4}$ nanoarrays towards allsolid-state hybrid supercapacitor with record-high energy density. Sci China Mater, 2021, 64: 852-860

$34 \mathrm{Xu} \mathrm{Y,} \mathrm{Zhu} \mathrm{J,} \mathrm{Feng} \mathrm{J,} \mathrm{et} \mathrm{al.} \mathrm{A} \mathrm{rechargeable} \mathrm{aqueous} \mathrm{zinc/sodium} \mathrm{man-}$ ganese oxides battery with robust performance enabled by $\mathrm{Na}_{2} \mathrm{SO}_{4}$ electrolyte additive. Energy Storage Mater, 2021, 38: 299-308

35 Fan X, Wang F, Ji X, et al. A universal organic cathode for ultrafast lithium and multivalent metal batteries. Angew Chem Int Ed, 2018, 57: 7146-7150

36 Mei $\mathrm{H}$, Huang $\mathrm{Z}, \mathrm{Xu} \mathrm{B}$, et al. $\mathrm{NiSe}_{2} / \mathrm{Ni}(\mathrm{OH})_{2}$ heterojunction composite through epitaxial-like strategy as high-rate battery-type electrode material. Nano-Micro Lett, 2020, 12: 61

37 Parker JF, Chervin CN, Pala IR, et al. Rechargeable nickel-3D zinc batteries: An energy-dense, safer alternative to lithium-ion. Science, 2017, 356: 415-418

38 Chang A, Zhang C, Yu Y, et al. Plasma-assisted synthesis of $\mathrm{NiSe}_{2}$ ultrathin porous nanosheets with selenium vacancies for supercapacitor. ACS Appl Mater Interfaces, 2018, 10: 41861-41865

39 Zhang S, Yang Z, Gong K, et al. Temperature controlled diffusion of hydroxide ions in 1D channels of Ni-MOF-74 for its complete conformal hydrolysis to hierarchical $\mathrm{Ni}(\mathrm{OH})_{2}$ supercapacitor electrodes. Nanoscale, 2019, 11: 9598-9607

40 Cui M, Bai X, Zhu J, et al. Electrochemically induced $\mathrm{NiCoSe}_{2} @$ $\mathrm{NiOOH} / \mathrm{CoOOH}$ heterostructures as multifunctional cathode materials for flexible hybrid Zn batteries. Energy Storage Mater, 2021, 36: 427434

41 Han C, Zhang T, Li J, et al. Enabling flexible solid-state $\mathrm{Zn}$ batteries via tailoring sulfur deficiency in bimetallic sulfide nanotube arrays. Nano Energy, 2020, 77: 105165

42 Zhai L, Benedict Lo TW, Xu ZL, et al. In situ phase transformation on nickel-based selenides for enhanced hydrogen evolution reaction in alkaline medium. ACS Energy Lett, 2020, 5: 2483-2491

43 Tang Y, Li X, Lv H, et al. Stabilized $\mathrm{Co}^{3+} / \mathrm{Co}^{4+}$ redox pair in in situ produced $\mathrm{CoSe}_{2-x}$-derived cobalt oxides for alkaline $\mathrm{Zn}$ batteries with 10 000-cycle lifespan and 1.9-V voltage plateau. Adv Energy Mater, 2020, 10: 2000892

44 Wang Q, Luo Y, Hou R, et al. Redox tuning in crystalline and electronic structure of bimetal-organic frameworks derived cobalt/nickel boride/ sulfide for boosted faradaic capacitance. Adv Mater, 2019, 31: 1905744

45 Zeng $\mathrm{Y}$, Lin Z, Wang Z, et al. In situ activation of 3D porous Bi/carbon architectures: Toward high-energy and stable nickel-bismuth batteries. Adv Mater, 2018, 30: 1707290

46 Zhang $\mathrm{Y}, \mathrm{Hu} \mathrm{Y}$, Wang $\mathrm{Z}$, et al. Lithiation-induced vacancy engineering of $\mathrm{Co}_{3} \mathrm{O}_{4}$ with improved Faradic reactivity for high-performance supercapacitor. Adv Funct Mater, 2020, 30: 2004172

47 Hou L, Shi Y, Wu C, et al. Monodisperse metallic $\mathrm{NiCoSe}_{2}$ hollow submicrospheres: Formation process, intrinsic charge-storage mechanism, and appealing pseudocapacitance as highly conductive electrode for electrochemical supercapacitors. Adv Funct Mater, 2018, 28: 1705921

$48 \mathrm{Ma} \mathrm{L}$, Chen $\mathrm{S}, \mathrm{Li} \mathrm{H}$, et al. Initiating a mild aqueous electrolyte $\mathrm{Co}_{3} \mathrm{O}_{4} /$ Zn battery with $2.2 \mathrm{~V}$-high voltage and 5000-cycle lifespan by a Co(III) rich-electrode. Energy Environ Sci, 2018, 11: 2521-2530

49 Tan Q, Li X, Zhang B, et al. Valence engineering via in situ carbon reduction on octahedron sites $\mathrm{Mn}_{3} \mathrm{O}_{4}$ for ultra-long cycle life aqueous Zn-ion battery. Adv Energy Mater, 2020, 10: 2001050

50 Wang S, Lai S, Li P, et al. Hierarchical cobalt oxide@nickel-vanadium layer double hydroxide core/shell nanowire arrays with enhanced areal specific capacity for nickel-zinc batteries. J Power Sources, 2019, 436: 226867

51 Pang Q, Sun C, Yu Y, et al. $\mathrm{H}_{2} \mathrm{~V}_{3} \mathrm{O}_{8}$ nanowire/graphene electrodes for aqueous rechargeable zinc ion batteries with high rate capability and large capacity. Adv Energy Mater, 2018, 8: 1800144

52 Zhong C, Liu B, Ding J, et al. Decoupling electrolytes towards stable and high-energy rechargeable aqueous zinc-manganese dioxide batteries. Nat Energy, 2020, 5: 440-449

53 Su L, Liu L, Wang Y, et al. Synergetic ternary metal oxide nanodotsgraphene cathode for high performance zinc energy storage. Chin Chem Lett, 2020, 31: 2358-2364

Acknowledgements This work was supported by the National Natural Science Foundation of China (21875285 and 22001265), Taishan Scholar Foundation (ts201511019), the Key Research and Development Projects of Shandong Province (2019JZZY010331), the Fundamental Research Funds for 
the Central Universities (19CX05001A), and the Natural Science Foundation of Shandong Province (ZR2020QB028).

Author contributions Mei $\mathrm{H}$ finished the experimental section, data analysis, and original draft writing. Zhang $\mathrm{H}$ helped with data analysis. Li Z and Zhang $\mathrm{L}$ helped with characterizations and analysis. $\mathrm{Lu} \mathrm{X}, \mathrm{Xu} B$ and Sun $\mathrm{D}$ revised the article.

Conflict of interest The authors declare that they have no conflict of interest.

Supplementary information Supporting data are available in the online version of the paper.

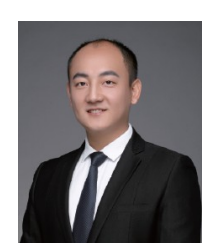

Ben $\mathrm{Xu}$ received his $\mathrm{PhD}$ degree from the Memorial University of Newfoundland in 2015. Currently, his main research interests focus on the design and synthesis of functional porous materials and their applications in the field of electrochemical energy storage.

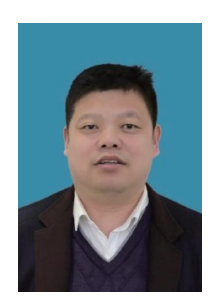

Daofeng Sun received his $\mathrm{PhD}$ degree from Fujian Institute of Research on the Structure of Matter, Chinese Academy of Sciences in 2003. Then, he conducted his postdoctoral work at the Department of Chemistry and Biochemistry, University of Miami. He joined China University of Petroleum in 2013. His main research interests focus on the design and synthesis of crystalline porous materials, high selectivity gas adsorbents and separation membranes, and energy storage and conversion materials.

\section{在水系锌电池中通过孔相双调控实现碳纳米管@硒 化镍的快速动力学活化}

梅豪 ${ }^{1}$, 张昊兵 ${ }^{1}$, 李紫祎 ${ }^{1}$, 张玲 ${ }^{1}$, 鲁效庆 ${ }^{1}$, 徐奔 ${ }^{1,2^{*}}$, 孙道峰 ${ }^{*}$

摘要 金属硫系化合物作为水相锌电池的高性能阴极具有很大的潜力. 然而, 低可达表面和剧烈的体积膨胀限制了其整体性能和实际应用. 为 此, 采用相工程策略结合空心结构设计, 调控 $\mathrm{OH}^{-}$在电极表面的吸附/ 脱附, 能显著提高电极的整体电化学性能. 本研究首次利用 $\mathrm{Se} @ \mathrm{C}$ 纳米 棒模板, 通过原位硒化过程可控合成了一系列碳纳米管(CNT)负载的 镍硒化物, 包括立方型 $\mathrm{NiSe}_{2} 、 \mathrm{NiSe}_{2} / \mathrm{Ni}_{0.85} \mathrm{Se}$ 复合材料、六方型 $\mathrm{Ni}_{0.85} \mathrm{Se}$. 优化后的 $\mathrm{NiSe}_{2} / \mathrm{Ni}_{0.85} \mathrm{Se} / \mathrm{CNT}$ 复合材料具有比表面积大、孔隙率高、碳 骨架空心等优点, 具有 $616 \mathrm{C} \mathrm{g}^{-1}$ 的高比容量、优良的倍率性能和稳定的 循环寿命. 通过一系列的非原位表征和DFT计算, 深入研究了其内部的 法拉第机制. 结果表明, 所制备的 $N i / / Z n$ 电池在 $3485 \mathrm{~W} \mathrm{~kg}^{-1}$ 时具有 $311.4 \mathrm{~W} \mathrm{~h} \mathrm{~kg}^{-1}$ 的高能量密度和较长的循环寿命. 本研究为硒化镍基电 极材料的设计提供了一种巧妙的策略, 且深入研究了其在碱性锌电池 中的法拉第机理. 